\title{
JUROS SIMPLES E COMPOSTOS: ANÁLISE DA PERCEPÇÃO DOS ALUNOS À LUZ DA TECNOLOGIA DO SOFTWARE CALC
}

\author{
SIMPLE AND COMPOUND INTERESTS: ANALYSIS OF THE PERCEPTION \\ IN THE LIGHT OF THE CALC SOFTWARE TECHNOLOGY
}

\author{
CLAUDIA FRANCISCO PELATI TEIXEIRA ${ }^{1}$ \\ JOÃO COELHO NETO
}

\section{RESUMO}

0 presente artigo trata do desenvolvimento e resultados de uma experiência didática voltada para 0 ensino de Juros Simples e Compostos, utilizando-se da Tendência Metodológica de ensino da Matemática: Mídias tecnológicas, agregando o software Calc como recurso auxiliador ao processo de ensino, por meio de uma Sequência Didática, com questões contextualizadas, voltadas para discentes do Ensino Médio. Utilizou-se a Análise Textual Discursiva de modo a unitarizar os dados do corpus e agrupá-los em categorias, entre elas e abordada nesse artigo, a utilização do recurso tecnológico Calc, que foi organizado com os excertos dos participantes e exploradas as sínteses e respectivas análises interpretativas. Os resultados revelaram uma análise favorável, sendo a Sequência Didática uma proposta articulada ao uso do Calc que se adequa ao ensino de Juros Simples e Compostos, permitindo apontamentos sobre a transformação da prática de ensino, bem como a mudança de postura pedagógica proporcionada pela inovação tecnológica digital.

Palavras-chave: Tecnologias Digitais. Juros Simples e Compostos. Planilha Eletrônica Calc. Sequência Didática. Ensino Médio.

\section{ABSTRACT}

This article deals with the development and results of a didactic experience focused on the teaching of Simple and Compound Interest, using the Methodological Trend of teaching Mathematics: Technological Media, adding the software Calc as a supporting resource to the teaching process, through a Didactic Sequence, with contextualized questions, aimed at high school students. The Discursive Textual Analysis was used to unitarize the data of the corpus and group them into categories, among them, the one approached in this article, the use of the technological resource Calc, which was organized with the excerpts of the participants and explored the syntheses and their interpretative analysis. The results revealed a favorable analysis, being the Didactic Sequence, an articulated proposal to the use of the Calc, that is adequate to the teaching of Simple and Compound Interest, allowing notes on the transformation of the teaching practice, as well as the change of pedagogical posture provided by the digital technological innovation.

Keywords: Digital Technologies. Simple and Compound Interest. Electronic Spreadsheet Calc. Didactic Sequence. High school.

\section{RESUMEN}

Este artículo trata sobre el resultados de una experiencia didáctica enfocada en la enseñanza del Interés Simple y Compuesto utilizando las Medios tecnológicos, agregando el software Calc como recurso auxiliar al proceso de enseñanza, a través de una Secuencia Didáctica, con preguntas contextualizadas, dirigido a estudiantes de secundaria. 1 Mestre em Ensino. Professora da Secretaria de Estado da Educação do Paraná - Assaí - PR. E-mail: claudiapelatti@gmail.com. Orcid: https://orcid.org/0000-0001-6160-309X

2 Doutor em Informática. Professor do Programa de Pós-Graduação em Ensino da Universidade Estadual do Norte do Paraná Cornélio Procópio. E-mail: joaocoelho@uenp.edu.br. Orcid: https://orcid.org/0000-0002-6154-3266 
Se utilizó Análisis Textual Discriptivo con el fin de unificar los datos del corpus y agruparlos en categorías, entre ellos y se discutió en este artículo, el uso del recurso tecnológico Calc, el cual se organizó con los extractos de los participantes y exploró las síntesis. y respectivos análisis interpretativos. Los resultados revelaron un análisis favorable, la Secuencia Didáctica, una propuesta articulada al uso de Calc, que es apta para la enseñanza del Interés Simple y Compuesto, permitiendo apuntes sobre la transformación de la práctica docente, así como el cambio en la postura pedagógica brindada, para la innovación tecnológica digital.

Palabras-clave Tecnologías digitales. Interés simple y compuesto. Hoja de cálculo electrónica Calc. Siguiendo la enseñanza. Escuela secundaria.

\section{INTRODUÇÃO}

As tecnologias digitais se tornaram aliadas com relação às práticas pedagógicas e apesar de não se apresentarem como a solução dos problemas educacionais de ensino de conteúdos em sala de aula, oferecem muitas possibilidades de reformular e inovar o modo de dar aulas, apresentar $\mathrm{e}$ ministrar os conteúdos, além de contribuir para promoção da cidadania.

Para Borba e Penteado (2016, p. 17),

0 acesso à informática deve ser visto como um direito e, portanto, nas escolas públicas e particulares o estudante deve poder usufruir de uma educação que no momento atual inclua, no mínimo, uma alfabetização tecnológica[...]. Assim, o computador deve ser inserido às atividades essenciais, tais como aprender a ler e escrever, compreender textos, entender gráficos, contar e nesse sentido, a escola passa a fazer parte das questões ligadas à cidadania.

Para tanto, os softwares podem ser desenvolvidos para fins educativos. Alguns dos softwares disponíveis que não foram criados para fins educativos, são instrumentos que podem auxiliar no processo de ensino e de aprendizagem, principalmente para a área de Matemática, visto que podem ser explorados ou aplicados no processo de ensino de alguns conteúdos, como o software Calc, planilha eletrônica de cálculo, utilizado nessa pesquisa para o ensino de Juros Simples e Composto.

De acordo com Borba, Silva e Gadanidis (2018, p. 21), "As dimensões da inovação tecnológica permitem a exploração e o surgimento de cenários alternativos para a educação e, em especial, para o ensino e aprendizagem de Matemática".

Um dos motivos para se utilizar as Planilhas Eletrônicas para o ensino de Matemática Financeira não é apenas o cálculo rápido e preciso, mas a redução do tempo gasto com cálculos repetitivos e já conhecidos.

0 trabalho foi direcionado para o ensino dos conteúdos de Juros Simples e Compostos por meio do software Calc, por considerar a importância e 0 impacto que o ensino desses conteúdos da Matemática Financeira pode ter em sensibilizar nas pessoas o pensamento crítico em práticas financeiras de consumo e interpretação de dados, mediante novos padrões tecnológicos incorporados à educação e a sociedade.

Para Borba, Silva e Gadanidis (2018, p. 41), relatam que esta junção de tecnologia digital com o ensino pode ser um diferencial no processo educacional, visto que

[...] inovações tecnológicas possibilitam a constituição de cenários qualitativamente diferenciados de investigação matemática; quando o uso pedagógico de um novo 
recurso tecnológico traz originalidade ao pensar-com-tecnologias. Esses desenvolvimentos estão intrinsecamente envolvidos com outros aspectos, como a elaboração de novos tipos de problemas [...], novas possibilidades ou reorganização de dinâmicas em sala de aula, dentre outros.

Com base nessas abordagens, o objetivo geral deste trabalho é investigar a viabilidade de ensino de Juros Simples e Composto, utilizando-se do software Calc, por meio da elaboração e aplicação de uma Sequência Didática.

Este trabalho faz parte de uma pesquisa de mestrado, apoiando-se em um vasto e robusto procedimento epistêmico e de aplicação sobre a temática aqui debatida.

Desse modo, este trabalho foi divido em cinco seções: a primeira seção contextualiza a temática e direciona o objetivo geral; na segunda seção, a fundamentação teórica é direcionada, a fim de apoiar as análises; na terceira seção, o encaminhamento metodológico é apreciado; na quarta seção, a visão geral da Sequência Didática desenvolvida; na quinta seção, as análises à luz da Análise Textual Discursiva é apresentada; na quinta e última seção, as considerações finais do trabalho desenvolvido.

\section{FUNDAMENTAÇÃO TEÓRICA}

Nesta seção serão abordados os temas base para a estruturação e articulação teórica para a sustentação dos resultados desta pesquisa.

\section{As Tecnologias Digitais voltadas para o Ensino}

0 termo tecnologia considera métodos e técnicas que visam à aplicação prática do conhecimento científico por meio das inovações direcionadas a resolver problemas. Consequentemente, as tecnologias digitais são, na prática, aplicativos digitais programados para uma finalidade que, quando utilizados ou criados para fins educativos, são chamados de tecnologia digital educacional. Segundo Valente (1999, p. 2),

[...] A informática na educação que estamos tratando, enfatiza o fato de que o professor da disciplina curricular ter conhecimento sobre os potenciais educacionais do computador e ser capaz de alternar adequadamente atividades tradicionais de ensino-aprendizagem e atividades que usam o computador.

As tecnologias digitais no contexto educacional assumem caráter de recurso auxiliador e colaborador do processo de ensino e aprendizagem.

Ensinar e aprender são faces do mesmo processo. As pessoas, no caso os discentes, não aprendem por igual, sendo a solidez do conhecimento algo muito pessoal, mas é papel da escola contribuir para que isso ocorra.

Generoso et al. (2013) abordam que ainda há a necessidade de capacitação do uso dos recursos tecnológicos no contexto educacional, principalmente por parte dos professores, para que estes possam ter acesso, pois esses instrumentos estão inseridos em toda a sociedade contemporânea e seu uso pode ser 0 diferencial para 0 ensino. 
A integração da informática aos conteúdos do currículo escolar é um fator fundamental e expressivo, agrega valor ao modo de ministrar as aulas, mas requer disposição do professor e planejamento.

Kenski $(2015$, p. 57) reafirma a preocupação na articulação das tecnologias com a educação quanto ao ensino de conteúdos e elenca os principais problemas:

0 primeiro deles é a falta de conhecimento dos professores para 0 melhor uso pedagógico da tecnologia... os professores não são formados para 0 uso pedagógico das tecnologias [...] 0 segundo problema é a não adequação da tecnologia ao conteúdo que vai ser ensinado e os propósitos do ensino. Cada tecnologia tem a sua especificidade e precisa ser compreendida como um componente adequado no processo educativo.

Esse contexto também pode ser observado em Coelho Neto e Altoé (2011, p. 2316), quando referem que:

0 uso da informática não tem sido fácil, posto que convivem sua ausência, na formação dos professores, e equipamentos insuficientes. Percebe-se, todavia, que, a despeito das adversidades, há professores concebendo o computador como mais um aliado no processo de melhoria do ensino, e por isso continuam a empenhar-se, mesmo que, por vezes, de forma solitária.

Portanto, em conformidade com a nova Base Nacional Comum Curricular (BNCC) (BRASIL, 2018, p. 528), destaca que

Além disso, a BNCC propõe que os estudantes utilizem tecnologias, como calculadoras e planilhas eletrônicas, desde os anos iniciais do Ensino Fundamental. Tal vaIorização possibilita que, ao chegarem aos anos finais, eles possam ser estimulados a desenvolver o pensamento computacional, por meio da interpretação e da elaboração de algoritmos, incluindo aqueles que podem ser representados por fluxogramas.

Moran, Masetto e Behrens (2001) consideram que o sucesso do ensino, em nosso caso 0 ensino da Matemática, depende e muito da capacidade de mobilizar o interesse e a disposição dos alunos para aprendizagem, pois é necessário ter argumentos convincentes e atualizados, como é 0 caso da necessidade do ensino da Matemática Financeira e sua articulação com as tecnologias.

Para tanto, alguns softwares são desenvolvidos para fins educativos; outros, porém, podem ser adaptados, como a planilha eletrônica de cálculo, o Calc, mas sempre com a finalidade de auxiliar ao processo de ensino e aprendizagem.

\section{Planilha Eletrônica}

É imprescindível mostrar ao aluno a grande capacidade de cálculo e armazenamento do computador para efetuar trabalhos que normalmente demandariam muito tempo e seriam resolvidos com uma calculadora, lápis e papel. Nesse contexto, Marchi (2014, p. 17) considera que 
[...] os computadores com seus aplicativos voltados para os cálculos financeiros, é uma realidade presente na sociedade. Saber dominar esses recursos se faz necessário, pois são de grande valia. As Planilhas Eletrônicas realizam cálculos e possibilitam não só expressar as informações graficamente, mas também organizar dados por meio de demonstrativos.

As planilhas de cálculo são definidas por seu formato e função, tendo sido pensadas e configuradas para satisfazer uma organização da disposição de cálculos, normalmente financeiros, que passaram por desenvolvimento e evolução, chegando às atuais planilhas eletrônicas de cálculo (BRASIL, 2006).

Uma das possibilidades que podem ser agregadas ao uso da planilha eletrônica no contexto do ensino da Matemática Financeira é o software Calc, a primeira planilha eletrônica (folha de cálculo), lançada em 1979, por Daniel Brichline da Universidade de Harvard (EUA). Ao inquietar-se por passar muito tempo fazendo cálculos em uma planilha de controle, teve a ideia de automatizar o processo; desde então, o software Calc evoluiu, aperfeiçoando seus recursos, livre de qualquer dependência financeira do programa vinculado a eles. É um software gratuito, sendo possível sua utilização em todos os níveis e sistemas de ensino (DIAS, 2013).

A respeito do uso das planilhas eletrônicas no ensino de Matemática, Brasil (2006, p.89) menciona que "[...] as planilhas eletrônicas, mesmo sendo ferramentas que não foram pensadas para propósitos educativos, também podem ser utilizadas como recursos tecnológicos úteis à aprendizagem matemática".

De acordo com Reis (2013, p. 34), as planilhas eletrônicas oferecem mais recursos importantes do ponto de vista pedagógico, a saber:

[...] oferecem a possibilidade de manusear os dados das atividades de forma mais dinâmica e com menos uso de teclas, uma vez que as fórmulas e dados digitados em uma célula podem ser generalizados para outras por meio do recurso de arrastar. [...] geram automaticamente um registro tanto das operações e funções matemáticas empregadas no problema, quanto dos dados da solução [...].

A essência do emprego do software Calc ou de outros softwares no ensino da Matemática está na tentativa de que os recursos sejam usados para trazer melhorias efetivas para a escola e seus alunos realizarem transformações na dinâmica das aulas e, consequentemente, promover 0 ensino. Dias (2013, p. 8) destaca que:

[...] Desta forma, as planilhas eletrônicas, aliadas à didática da contextualização matemática, permitem várias formas de representação semiótica, dando ao educando a oportunidade de construir, visualizar, manipular, interiorizar, abstrair e tirar conclusões, a partir de situações prováveis, escolhidas por eles, ou pelo professor, e trabalhadas em sala de aula de forma dinâmica e interativa.

É imprescindível o lançamento, organização dos dados e o raciocínio na elaboração das fórmulas, pois é o principal trabalho matemático do aluno ao contar com o auxílio do Calc, uma vez que 0 software possui grande potencialidade de cálculo, organização e armazenamento dos dados, 
especialmente ao efetuar trabalhos que normalmente iriam demandar muito tempo para serem resolvidos "à mão" e que certamente necessitariam contar com apoio de uma calculadora, lápis e papel. Nesse contexto, Marchi (2014, p. 17) considera que:

[...] os computadores com seus aplicativos voltados para os cálculos financeiros, é uma realidade presente na sociedade. Saber dominar esses recursos se faz necessário, pois são de grande valia. As Planilhas Eletrônicas realizam cálculos e possibilitam não só expressar as informações graficamente, mas também organizar dados por meio de demonstrativos.

Parte-se do pressuposto que as vantagens oferecidas pelo uso adequado das planilhas eletrônicas quando associadas às necessidades dos conteúdos matemáticos, para esse caso Juros Simples e Compostos, venha a favorecer de modo mais significativo a aprendizagem do aluno, uma vez que 0 método de ensino para esse conteúdo pode se apoiar em tecnologias digitais, de modo a auxiliar no processo de compreensão do conteúdo.

\section{ENCAMINHAMENTOS METODOLÓGICOS}

As tendências de ensino voltadas ao ensino da Matemática são vistas como um saber dinâmico e vivo, construídos para atender às demandas das transformações da sociedade.

De acordo com Paraná (2008), os encaminhamentos metodológicos para o ensino da Matemática são: a Resolução de Problemas, Modelagem Matemática, Investigação, Etnomatemática, História da Matemática e Mídias tecnológicas, os quais possuem graus de importância similares entre si, complementando-se uns aos outros. Dentro da categorização proposta, neste trabalho utilizar-se-á a tendência Mídias Tecnológicas.

Assim, parte-se do pressuposto de que 0 ensino dos conteúdos, por meio da metodologia Mídias Tecnológicas, quando executados com 0 auxílio de algum software computacional pode vir a dinamizar o ensino dos conteúdos e potencializar o processo pedagógico. Segundo Borba e Penteado (2016, p. 17)

[...] Desse modo, 0 acesso a informática na educação deve ser visto não apenas como um direito, mas como parte de um projeto coletivo que prevê a democratização de acesso a tecnologias desenvolvidas por essa mesma sociedade. É dessas duas formas que a informática na educação deve ser justificada: alfabetização tecnológica e direito ao acesso.

Portanto, a integração das Mídias Tecnológicas ao ensino dos conteúdos matemáticos é uma metodologia que naturalmente transforma a aula e desconfigura a previsibilidade das aulas tradicionais. É um recurso inovador, cabendo ao docente encontrar a forma mais adequada de articular 0 método de ensino do conteúdo matemático às tecnologias digitais disponíveis. 
0 presente trabalho configura-se como pesquisa qualitativa, norteado pelo estudo e elaboração de uma Sequência Didática. Portanto, a seguir será contemplado o tratamento que se teve quanto à Sequência Didática.

\section{PROPOSTA DA SEQUÊNCIA DIDÁTICA}

Apoiada pela prática educativa de como ensinar, proposta por Zabala (2010), considera-se, portanto, a elaboração de um conjunto de atividades contextualizadas e planejadas para ensinar 0 conteúdo de Juros Simples e Compostos com auxílio do software Calc.

Zabala (2010, p.20) explica que:

As sequências de atividades de ensino/aprendizagem, ou sequências didáticas, são uma maneira de encadear e articular as diferentes atividades ao longo de uma unidade didática [...]. As sequências podem indicar a função que tem cada uma das atividades na construção do conhecimento ou da aprendizagem de diferentes conteúdos e, portanto, avaliar a pertinência ou não de cada uma delas, a falta de outras ou a ênfase que devemos the atribuir.

0 público-alvo de participantes da pesquisa foi constituído de 18 (dezoito) alunos, matriculados no $3^{\circ}$ ano A - Matutino, de uma escola pública do norte do Paraná. Antes da aplicação da Sequência Didática, ocorreu a entrega do Termo de Consentimento aos alunos menores de 18 anos para coIherem assinatura dos seus respectivos pais, bem como o Termo de Assentimento para a ciência e assinatura dos próprios alunos, afirmando ter ciência de que a aplicação desta sequência culminaria em trabalhos científicos. Os alunos têm seus nomes reservados e a fim de preservar suas identidades, são apresentados na pesquisa por códigos iniciando em A1 (aluno 1), A2 (aluno 2), A3,... A18.

A aplicação da Sequência ocorreu integralmente no laboratório de informática do Colégio, 0 qual dispõe de infraestrutura adequada com os recursos necessários, no caso computadores em bom estado de uso e com o sistema Linux, um conjunto de softwares livres, entre eles a planilha Calc.

Para o desenvolvimento das questões da Sequência, foram levadas em consideração as aprendizagens dos conteúdos conceituais, procedimentais e factuais:

- Conceitual: as questões permitem que os alunos relacionem o conteúdo a fatos ou situações associando-os ao significado de Juros, Juros Simples e Compostos, por meio de uma compreensão que vai além da reprodução, é o "saber usar", aplicar, situar o significado à sua funcionalidade;

- Procedimental: aplicar um conjunto de ações ordenadas, no caso, ler, interpretar e calcular, com procedimentos que apresentam uma condição "sine qua non", passando pela exercitação múltipla das atividades como elemento necessário para o domínio das ações ou passos na busca da resolução das questões;

- Atitudinal: são exercícios que exigem real compreensão e menor memorização, 0 aluno reconhece o conteúdo na questão e procura resolvê-la autonomamente (ZABALA, 2010).

Isso posto, foi elaborada a tabela 1, que sumariza as características das atividades que formam a Sequência Didática elaborada. 
Tabela 1 - Características das Questões da Sequência Didática desenvolvida.

\begin{tabular}{|c|c|c|c|}
\hline Oficinas & Ativ. & $\begin{array}{l}\text { Classificação prioritária } \\
\text { do Conteúdo Zabala } \\
\text { (2010) }\end{array}$ & Objetivos das Questões \\
\hline \multirow{5}{*}{$\begin{array}{l}\text { Oficina } 1 . \\
\text { Reconhecimento dos } \\
\text { recursos do software Calc } \\
\text { e conceito de juros }\end{array}$} & 1 & Conceitual & $\begin{array}{l}\text { Explorar a área de trabalho da Planilha Calc em busca de informações e assim } \\
\text { elaborar conclusões. }\end{array}$ \\
\hline & $\begin{array}{l}2,3 \\
4 \text { e } 5\end{array}$ & Procedimental & $\begin{array}{l}\text { Problemas e questões para a elaboração da fórmula para as } 4 \text { operações, } \\
\text { potência, raiz, \% e logaritmos. }\end{array}$ \\
\hline & 6 & Atitudinal & $\begin{array}{l}\text { Questões para respostas subjetivas para descrever as vantagens e dificuldades } \\
\text { do software Calc. }\end{array}$ \\
\hline & 7 & Conceitual & Situação problema de indução ao conceito de Juros. \\
\hline & 8 & Atitudinal & Avaliação subjetiva sobre aprendizagens e dificuldades da oficina. \\
\hline \multirow{6}{*}{$\begin{array}{l}\text { Oficina } 2 . \\
\text { Juros Simples }\end{array}$} & 1 & Conceitual & $\begin{array}{l}\text { Introdução a Juros simples por meio de situação problema para identificar } \\
\text { capital, taxa e tempo para generalização da fórmula de Juros Simples. }\end{array}$ \\
\hline & 2 & Conceitual & $\begin{array}{l}\text { Respostas intuitivas das operações matemáticas utilizadas para generalização } \\
\text { da fórmula e Montante Simples. }\end{array}$ \\
\hline & 3 e 4 & Procedimental & Exercícios de fixação de Juros e montante simples. \\
\hline & 5 e 6 & Procedimental & Cálculo do capital por meio da articulação da fórmula de Juros Simples. \\
\hline & 7 & Procedimental & Generalização da fórmula de Juros Simples para capital e tempo \\
\hline & 8 & Atitudinal & Atividade Avaliativa subjetiva sobre as aprendizagens e dificuldades da aula. \\
\hline \multirow{5}{*}{$\begin{array}{l}\text { Oficina } 3 . \\
\text { Montante e Juros } \\
\text { Compostos }\end{array}$} & 1 & Conceitual & $\begin{array}{l}\text { Indução ao conceito de Juros Compostos por meio de situação problema e } \\
\text { generalização da fórmula. }\end{array}$ \\
\hline & 2 & Conceitual/ Procedimental & Generalização da fórmula de Juros e Montante Compostos. \\
\hline & 3 & Procedimental & $\begin{array}{l}\text { Executar o cálculo de Montante e Juros Compostos por meio da fórmula } \\
\text { desenvolvida. }\end{array}$ \\
\hline & 4 & $\begin{array}{l}\text { Conceitual } \\
\text { Procedimental } \\
\text { Atitudinal }\end{array}$ & Isolar incógnitas tempo, capital e taxa na fórmula de Montante Compostos. \\
\hline & 5 & Atitudinal & Atividade Avaliativa subjetiva sobre as aprendizagens e dificuldades da aula. \\
\hline \multirow{4}{*}{$\begin{array}{l}\text { Oficina } 4 \text {. } \\
\text { Atividades para cálculo de } \\
\text { taxa, tempo e capital } \\
\text { para Juros Compostos. }\end{array}$} & 1 e 2 & $\begin{array}{l}\text { Conceitual e } \\
\text { Procedimental }\end{array}$ & $\begin{array}{l}\text { Calcular a taxa de Juros Compostos com a fórmula generalizada na oficina } \\
\text { anterior e exercício de fixação. }\end{array}$ \\
\hline & 3 e 4 & $\begin{array}{l}\text { Conceitual e } \\
\text { Procedimental }\end{array}$ & Calcular o capital nos Juros Compostos e exercício de fixação. \\
\hline & 5 e 6 & $\begin{array}{l}\text { Conceitual e } \\
\text { Procedimental }\end{array}$ & Calcular o tempo nos Juros Compostos e exercício de fixação. \\
\hline & 7 & Atitudinal & Atividade Avaliativa subjetiva sobre as aprendizagens e dificuldades da aula. \\
\hline \multirow{3}{*}{$\begin{array}{c}\text { Oficina } 5 . \\
\text { Atividade comparativa } \\
\text { entre Juros Simples, } \\
\text { Compostos, } \\
\text { Gráfico comparativo e } \\
\text { Avaliação Final }\end{array}$} & 1 & Atitudinal & $\begin{array}{l}\text { Questão de cunho comparativo de cálculo e gráfico entre Juros Simples e } \\
\text { Compostos. }\end{array}$ \\
\hline & 2 & Atitudinal e Procedimental & $\begin{array}{l}\text { Resolver a atividade avaliativa por meio de questão de cálculo de Montante } \\
\text { Simples e Compostos e construir o gráfico comparativo entre as duas capita- } \\
\text { lizações. }\end{array}$ \\
\hline & 3 & Atitudinal & $\begin{array}{l}\text { Atividade Avaliativa subjetiva sobre as aprendizagens e dificuldades encontra- } \\
\text { das para resolver as questões da Sequência Didática no software Calc. }\end{array}$ \\
\hline
\end{tabular}

Fonte: Os autores.

As atividades foram distribuídas progressivamente por nível de dificuldade, exigindo dos alunos a análise, síntese e avaliação reflexiva da atividade (consequentemente do professor), construindo um caminho para resolvê-la e, ao mesmo tempo, promovendo o progresso da aprendizagem. 
A Sequência Didática elaborada foi analisada intersubjetivamente por dois professores especialistas na área de Ensino e Educação Matemática, atuantes na área de pesquisas e com experiência docente na Educação Básica. Também foi analisada por docente do Ensino Médio, a fim de verificar a viabilidade e aplicabilidade, bem como a necessidade de adequações nessa sequência para o contexto escolar. Tais contribuições foram implementadas à estrutura da sequência, com intuito de melhorar a qualidade da Sequência Didática.

Todos os exercícios/problemas/atividades ou questões foram construídos de modo global, como um todo, jamais fragmentado, contendo informações que procuram dar sentido ao conteúdo, contemplando a vivência e anseios dos alunos ou o meio no qual estão inseridos.

\section{Aplicação da Sequência Didática}

Consideramos aconselhável a aplicação para alunos do Ensino Médio, podendo ocorrer para $03^{0}$ ano ou outra série que já tenha assimilado quesitos mínimos de conteúdos, uma vez que se espera um embasamento teórico de conteúdos prévios, como é o caso, por exemplo, dos logaritmos, necessários para resolver algumas das questões propostas em Juros Compostos.

As oficinas foram organizadas e aplicadas em três momentos:

- A primeira oficina (2 aulas) consiste na apresentação de um manual da Planilha Calc e a conceituação do termo Juros. Ocorre, de início, o contato do aluno com o software da planilha Calc e a navegação pela sua tela para reconhecer seus ícones e recursos. Os alunos consultam o manual para formação de fórmulas, realizam cálculos básicos e elementares, cujo propósito é oferecer subsídios suficientes para a resolução das questões propostas na sequência. Segue a resolução das questões com uma problemática sobre a conceituação de juros em que 0 aluno é levado a descrever sua compreensão sobre a situação do problema e, consequentemente, generalizar 0 conceito de juros. Culmina-se no registro da autoavaliação das facilidades e das dificuldades que 0 aluno tenha encontrado durante a oficina.

Figura 1 - Desenvolvimento da $1^{\mathrm{a}}$ Oficina.

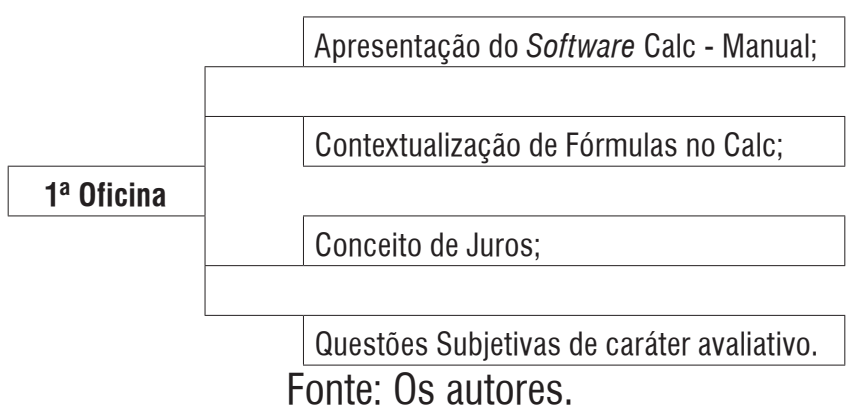

- Na segunda oficina (2 aulas) os alunos realizam as atividades de Juros Simples, resolvendo-as em conformidade aos comandos de posicionamento na planilha eletrônica e citados nas atividades. Para o registro dos dados e elaboração das respectivas fórmulas, procuram generalizar a fórmula de Juros Simples, inclusive reconhecer e isolar as variáveis que compõem a fórmula e, por meio do isolamento de incógnita, como em uma equação do $1^{0}$ grau, flexibilizam a fórmula de Juros Simples para 
taxa, tempo e capital, que usará para resolução das próximas questões dessa oficina. Então, termina essa etapa avaliando seu próprio desempenho por meio de questões subjetivas sobre as dificuldades e facilidades que tiveram no decorrer dessa oficina.

Figura 2 - Desenvolvimento da $2^{\mathrm{a}}$ Oficina.

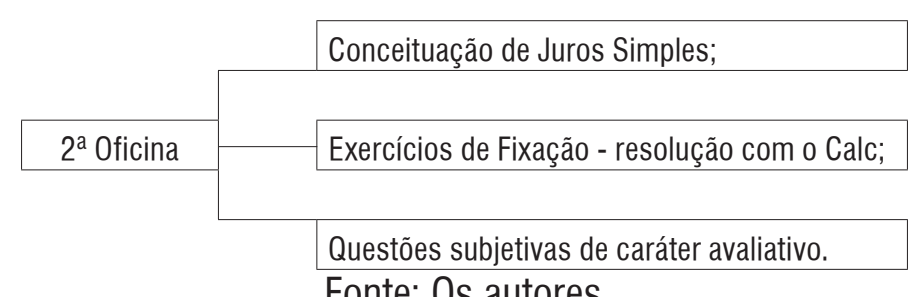

Fonte: Os autores.

- A terceira oficina (3 aulas) se refere ao ensino introdutório e conceitual de Juros Compostos. Para resolver a primeira questão, os alunos seguem os comandos de posicionamento e elaboração da fórmula na planilha Calc, de modo que a resolução atenda o sistema de capitalização composta para um mesmo capital e taxa até 0 terceiro mês. 0 propósito é conduzir os alunos à percepção de que os juros calculados no decorrer dos meses vão sendo incorporados ao capital e novamente os juros são calculados sobre esse montante. A questão propõe o cálculo no decorrer do tempo (meses), na tentativa de efetivação da generalização da fórmula de Montante Compostos.

Após os ajustes necessários à generalização da fórmula de Montante Composto, os exercícios foram elencados de modo a tentar isolar as variáveis da fórmula, a fim de obter a fórmula para taxa, tempo e capital, por meio de regras matemáticas. Ao final da oficina, descrevem as dificuldades e facilidades da aula, e, se necessário, retoma-se conteúdos matemáticos para subsidiarem o isolamento de incógnitas ou o cálculo.

Figura 3 - Desenvolvimento da $3^{a}$ Oficina.

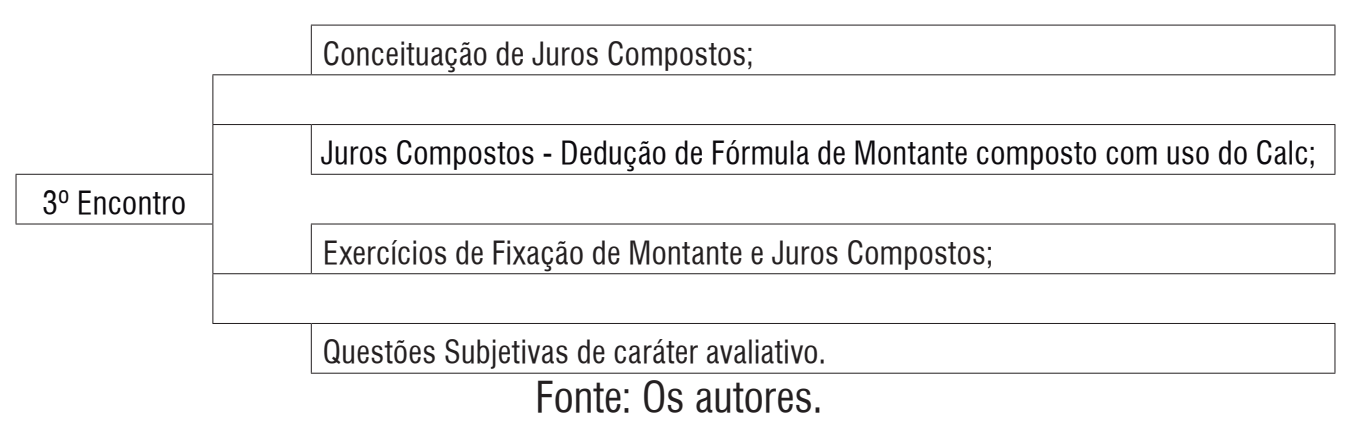

A principal característica da quarta oficina (2 aulas) está nos exercícios de fixação, pois a repetição das ações em exercícios de fixação busca proporcionar domínio, segurança e autonomia dos alunos. Quanto mais praticam, tornam-se mais habituados, revelando-se a importância do caráter procedimental das questões. 
Se necessário, o professor faz a retomada ou 0 ensino de conteúdos, a exemplo de equação exponencial, propriedades logarítmicas e potenciação, levando os alunos a criarem uma analogia de como isolar as incógnitas com o estudo prévio de conteúdos. Os alunos, após subsidiados pela retomada de conteúdos, devem dar continuidade à resolução das questões, articulando os dados na planilha Calc, utilizando as fórmulas generalizadas anteriormente e finalizando a etapa com o registro de suas percepções sobre a aula.

Figura 4 - Desenvolvimento da $4^{\mathrm{a}}$ Oficina.

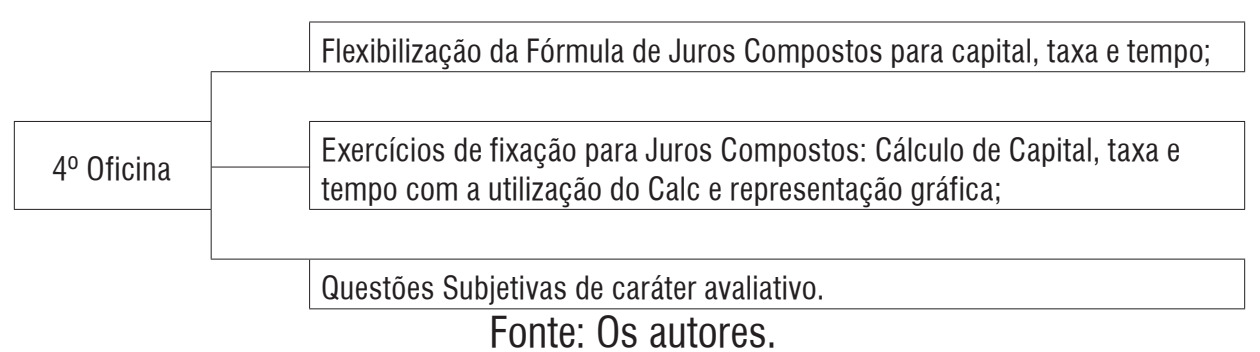

A finalidade principal da quinta oficina está em estabelecer um sistema comparativo entre os dois sistemas de Juros, Simples e Compostos, propondo uma atitude autônoma por parte do aluno com a resolução de exercício para cálculo do montante dos dois sistemas de capitalização e a mediação do professor para obter a representação gráfica da situação. Na sequência, a atividade avaliativa somativa, similar à anterior, deve ser resolvida pelos alunos, que gravam a planilha e a enviam por e-mail para correção.

Figura 5 - Desenvolvimento da $5^{\text {a }}$ Oficina.

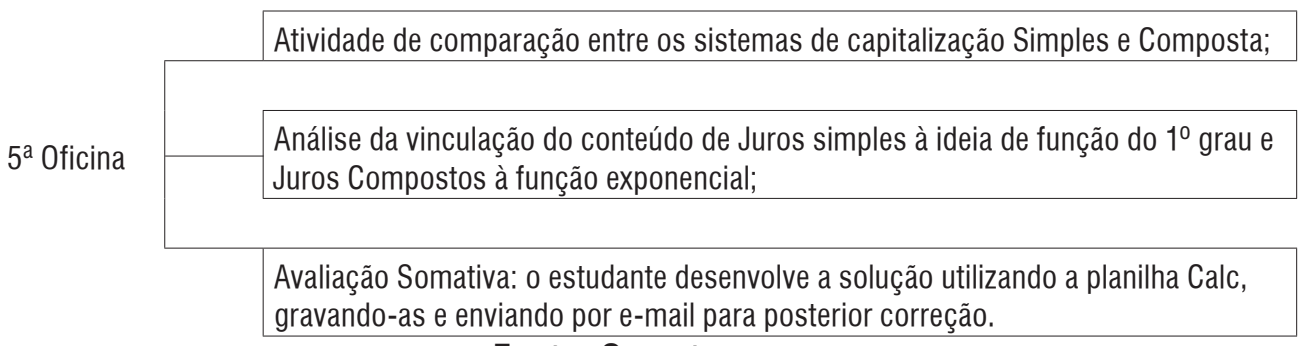

Fonte: Os autores.

0 desafio do movimento ensino e aprendizagem dos conteúdos de Juros Simples e Compostos por meio da resolução da Sequência Didática, articulada com a metodologia Mídias Tecnológicas, institui uma análise qualitativa dos dados em que são apresentadas algumas das análises dos resultados da aplicação da SD, ao qual elenca-se a apresentação das categorias, unidades e suas respectivas sínteses e interpretações acerca da temática analisada. 


\section{ANÁLISE DOS RESULTADOS}

Os resultados são oriundos de um contexto real de ensino por meio da aplicação da Sequência Didática desenvolvida que, para esse trabalho de pesquisa, ficaram estabelecidas a priori as categorias: Utilização do software Calc (propositalmente explorada nesse artigo); Adequação ao Raciocínio Matemático; Transcrição para a linguagem do recurso software Calc; e Conhecimentos Matemáticos, todos seguidos de suas unidades de análises, também estabelecidas a priori e/ou emergentes do processo.

Destarte, o pesquisador capta as ideias principais do contexto e passa a considerar as categorias "a priori" aquelas já planejadas antes da pesquisa, bem como pode construir as categorias "emergentes" que possam surgir na análise do material. Moraes e Galiazzi (2014, p. 117) apontam que:

Quando a opção é trabalhar com categorias a priori, o pesquisador deriva suas categorias de seus pressupostos teóricos, sejam explícitos ou implícitos. Nesse caso, as categorias já estão definidas antes de se encaminhar a análise e a classificação propriamente dita das unidades [...] Quando a opção é por categorias emergentes, o pesquisador assume uma atitude fenomenológica de deixar que os fenômenos se manifestem, construindo suas categorias a partir das múltiplas vozes emergentes nos textos que analisa.

As análises dos dados seguem uma metodologia de análise de caráter qualitativo, com a finalidade de produzir compreensões sobre as percepções dos alunos envolvidos na pesquisa.

\section{Unitarização e Categorização dos dados}

Para a análise dos dados coletados no processo de pesquisa, o enriquecimento da escrita reconstrutiva vai muito além da explicação de verdades explicitas ou não. É necessário, a partir de leituras de diferentes autores, inserir em forma de citação as corroborações desses autores como um norteamento acerca da tempestade de luz e explosão de ideias que transcendem naturalmente no processo de Análise Textual Discursiva.

Considera-se, ainda, a homogeneidade: "as categorias precisam ser construídas a partir de um mesmo princípio, de um mesmo contínuo conceitual (MORAES, 2003, p. 1999)", podendo haver subcategorias dependendo da complexidade dos dados; e a não exclusão mútua, pois a exclusão mútua "não se sustenta frente às múltiplas leituras (Moraes, 2003, p. 199)" dos dados, no sentido de superar a fragmentação.

\section{Categoria: Uso do software Calc}

A categoria Uso do Recurso Tecnológico software Calc foi estabelecida com o objetivo de analisar, junto aos alunos, suas percepções a respeito do auxílio que a tecnologia digital do software Calc pode proporcionar como um recurso colaborador do processo do ensino e aprendizagem do conteúdo de Juros Simples e Compostos. 
Em busca de captar as Dificuldades e Vantagens que o software Calc proporciona na prática, estes temas foram elencados como unidades de análise, sob o ponto de vista dos alunos em suas descrições nas respostas das questões subjetivas, em conformidade à Tendência Metodológica de Ensino denominada Mídias Tecnológicas, compondo, portanto, as unidades de análise quanto à utilização do software Calc para resolver as questões de Juros Simples e Compostos, conforme apresentado na Figura 6.

Figura 6 - Categoria uso do recurso tecnológico do software Calc.

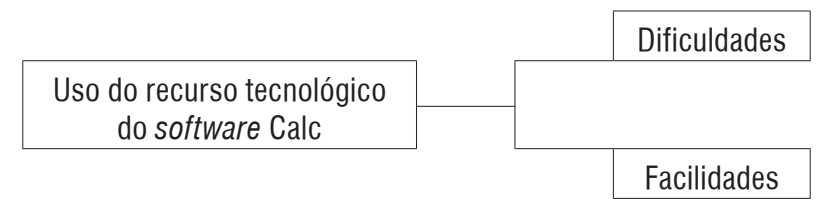

Fonte: Os autores.

Diante da ordem estrutural dos norteamentos de análise da pesquisa, tanto a categoria e suas respectivas unidades de análise, os metatextos sobre a síntese e interpretação dos dados, Moraes e Galiazzi (2014, p. 10) apontam que:

Em todos esses processos enfatiza-se o necessário envolvimento intenso e rigoroso do pesquisador no processo de análise e de reconstrução. Precisa assumir-se intérprete e autor, processo em que os resultados expressos representam modos de intervenção nos discursos sociais investigados.

0 processo de formação das unidades ocorre por semelhança. Conforme a Figura 6, as unidades Dificuldades e Facilidades foram direcionadas à utilização do recurso tecnológico Calc na resolução das questões propostas na Sequência Didática, ficando, portanto, estabelecida como uma das principais categorias de análise.

Isso posto, para os excertos são consideradas as representatividades das descrições e interpretações feitas, os quais precisam ser válidos e pertinentes aos objetivos da análise e representação dos dados da fundamentação teórica adotada, conforme o quadro a seguir. 
Quadro 1 - Unidade Dificuldades quanto ao Uso do recurso tecnológico do software Calc excertos e síntese descritiva das Dificuldades descritas.

\begin{tabular}{|c|c|}
\hline & \\
\hline & "[...] Entender alguns comandos [...]" (A5). \\
\hline \multicolumn{2}{|c|}{$\begin{array}{l}\text { Síntese Descritiva da unidade: } \\
\text { Quanto à primeira questão, sobre as dificuldades iniciais do processo, praticamente todos os alunos relataram na Of. } 1 \text { que tiveram } \\
\text { dificuldade na elaboração e digitação das fórmulas; porém, os comandos e o primeiro contato com o programa também foram elencados. } \\
\text { Com o decorrer do processo de resolução das atividades, no que se refere às dificuldades em usar a Planilha Calc para resolver as ques- } \\
\text { tões, é perceptível nas falas dos alunos que, apesar de ainda alguns apontarem a elaboração da fórmula no software Calc continuar sendo } \\
\text { uma das dificuldades, ainda persiste a citação sobre a dificuldade na manipulação das fórmulas. }\end{array}$} \\
\hline
\end{tabular}

Fonte: 0 s autores.

\section{Quadro 2 - Unidade Facilidades quanto ao Uso do recurso tecnológico do software Calc - excertos e síntese descritiva das Facilidades descritas.}

\begin{tabular}{|c|c|}
\hline Unidade Facilidades & \\
\hline $\begin{array}{l}\text { Quais facilidades você encon- } \\
\text { trou ao resolver as questões } \\
\text { com o auxílio do software } \\
\text { Calc? }\end{array}$ & $\begin{array}{l}\text { Oficina } 4 \text { - Questão 2c } \\
\text { "É um método mais rápido e fácil. Se fizer as fórmulas de modo correto, não tem erro." (A1) } \\
\text { - "Que o Calc fornece com muito mais facilidade as fórmulas e cálculos" (A6) } \\
\text { - "A velocidade que faz os cálculos e a precisão, pois juros é uma coisa difícil de resolver, imagina calcular } \\
\text { a exponencial de juros compostos na mão." (A7) } \\
\text { - "O Calc ajudou a entender a matemática financeira com facilidade, me preocupava com a matéria e não } \\
\text { com a conta." (A8) } \\
\text { - "Fazer cálculos muito grandes, que seria muito difícil fazer em outro lugar." (A11) }\end{array}$ \\
\hline \multicolumn{2}{|c|}{$\begin{array}{l}\text { Síntese Descritiva da unidade: } \\
\text { Quanto à primeira questão que aborda as vantagens da planilha Calc para resolver as questões da Sequência Didática, os alunos des- } \\
\text { crevem as qualidades e benefícios do trabalho com o auxílio do software Calc com palavras como precisão, prático, rápido e facilidade, } \\
\text { comuns a praticamente todas as descrições. } \\
\text { Consideram, ainda, que alguns cálculos são muito extensos se feitos à mão; principalmente no que se refere ao montante dos Juros } \\
\text { Compostos, devido ao tempo ser exponencial e se tratar de números decimais. } \\
\text { Quanto à segunda questão sobre as vantagens do Calc para resolver as questões no decorrer das aulas, há uma persistência com o uso } \\
\text { das palavras rápido e fácil. Existe também um consenso de que as fórmulas precisam estar corretas; caso contrário, o software não } \\
\text { responde ao comando da fórmula e acusa erro ao emitir o resultado. }\end{array}$} \\
\hline
\end{tabular}

Fonte: Os autores.

Chamou a atenção para a pesquisa, o fato de os alunos se mostrarem ambientalizados com o manuseio dos ícones na tela do software, provavelmente por serem comuns a outros softwares e demonstrando, portanto, o quanto os alunos estão envolvidos com as tecnologias digitais. 
A relação com a Mídia eletrônica é prazerosa - ninguém obriga que ela ocorra; é uma relação feita através da sedução, da emoção, da exploração sensorial, da narrativa - aprendemos vendo as histórias que os outros nos contam. Mesmo durante o período escolar a mídia mostra o mundo de outra forma - mais fácil, agradável, compacta, sem precisar fazer esforço. Ela fala do cotidiano, dos sentimentos, das novidades. A mídia continua educando como contraponto à educação convencional, educa enquanto estamos entretidos (MORAN; MASSETO; BEHRENS, 2001, p. 33)

Portanto, a planilha eletrônica oferece mais do que recursos importantes do ponto de vista pedagógico, como apresentado nas análises interpretativas que seguem.

\section{ANÁLISE INTERPRETATIVA}

Tendo em vista o envolvimento e interesse dos alunos em todo o processo de aprendizagem e exploração do software Calc revelado no processo da pesquisa e do desenvolvimento das oficinas, Kenski (2015, p. 103) trata da construção e aprofundamento do conhecimento:

[...] aproveitar o interesse natural dos jovens estudantes pelas tecnologias e utilizá- las para transformar a sala de aula em espaço de aprendizagem ativa e de reflexão coletiva; capacitar os alunos não apenas para lidar com as novas exigências do mundo do trabalho, mas, principalmente, para produção e manipulação das informações e para o posicionamento crítico diante dessa nova realidade.

Sendo, portanto, uma leitura e interpretação aprofundadas no modo de analisar os resultados oriundos da pesquisa e determinar os significados, ocorrem constantes movimentos de retomada voltados a esta compreensão mais profunda. 0 pesquisador é organizador, intérprete e autor, com envolvimento intenso e rigoroso na análise e reconstrução.

\section{DIFICULDADES QUANTO AO USO DO RECURSO TECNOLÓGICO DO SOFTWARE CALC}

A análise do corpus em relação às dificuldades elencadas pelos alunos no uso do Calc, possibilitou a percepção de que o manuseio com a área de trabalho da planilha e seus ícones não causou estranhamento aos alunos, uma vez que são itens comuns a outros programas e, em nenhum momento, se referiram ao manual ou alguma dificuldade com os ícones do programa.

Em conformidade à Base Nacional Comum Curricular (Brasil, 2018, p. 528)

[...] quando a realidade é a referência, é preciso levar em conta as vivências cotidianas dos estudantes do Ensino Médio - impactados de diferentes maneiras pelos avanços tecnológicos, pelas exigências do mercado de trabalho, pelos projetos de bem viver dos seus povos, pela potencialidade das mídias sociais, entre outros. Nesse contexto, destaca-se ainda a importância do recurso a tecnologias digitais e aplicativos tanto para a investigação matemática como para dar continuidade ao desenvolvimento do pensamento computacional, iniciado na etapa anterior. 
Desse modo, o conhecimento prévio que muitos alunos têm sobre os recursos computacionais comuns a outros aplicativos, nos leva a refletir sobre essa automatização do mundo da informática à qual nos condicionamos, assim como sobre o quanto os alunos estão inseridos no mundo tecnológico digital. Assim, Kenski (2015, p. 44) propõe:

\begin{abstract}
Pense um pouco em quantos processos e produtos você usa naturalmente em seu cotidiano e em como teve de se esforçar para aprender a utilizá-los. Talvez você nem os perceba como "tecnologias" que, em um determinado momento, revolucionaram a sua maneira de pensar, sentir e agir. Muitas pessoas, como você, passaram por esse mesmo processo, incorporaram inovações em suas vidas e, hoje, não conseguem mais viver sem elas. Assim, podemos ver que existe uma relação direta entre educação e tecnologias. Usamos muitos tipos de tecnologias para aprender e saber mais sobre as tecnologias.
\end{abstract}

Contudo, com o decorrer do processo de aplicação da sequência, conforme Questão 2b, aplicada na Oficina 3, sobre as dificuldades encontradas para desenvolver as atividades na planilha Calc durante as aulas de Juros Simples e Compostos, o principal problema descrito pelos alunos ficou direcionado mais especificamente à elaboração e digitação de fórmulas.

\title{
FACILIDADES QUANTO AO USO DO RECURSO TECNOLÓGICO DO SOFTWARE CALC
}

Quanto às facilidades que o uso software Calc proporciona, os alunos envolvidos na pesquisa se expressam com termos comuns em suas falas: praticidade, velocidade, agilidade e precisão dos cálculos, a exemplo do relato: "É um método mais rápido e fácil. Se fizer as fórmulas de modo correto, não tem erro." (A11 - Of. 1 - Q. 6a), revelando o reconhecimento ao apoio que o software ofereceu na resolução das questões da Sequência Didática.

Os alunos demonstram preocupação quanto à necessidade em entender o conteúdo e as informações postas nas questões para assim fazer a elaboração da fórmula, mas sem se preocupar com contas, pois essas são o software quem executa, conforme se revela no relato: "0 Calc ajudou a entender a matemática financeira com facilidade, me preocupava com a matéria e não com a conta." (A8 - Of. 4 - Q. 2C). Por conseguinte, ressalta-se que o uso do Calc possibilita maior compreensão da matéria por ele não ter de se preocupar em fazer os cálculos.

A impressão foi a de que 0 aluno considerou ter uma preocupação a menos; no caso o processo manual de cálculo. Portanto, a preocupação foi com a compreensão do real sentido do conteúdo.

Não se pode negar o impacto provocado pela tecnologia [...] tem-se nessa tecnologia um recurso que pode subsidiar o processo de aprendizagem da matemática. É importante contemplar uma formação escolar no sentido de utilizar a Matemática como ferramenta para entender a tecnologia, e a tecnologia como ferramenta para entender a Matemática (BRASIL, 2006, p. 87).

Quanto à metodologia de Mídias em relação às questões da Sequência Didática, ao se valerem do Calc para resolverem tais questões percebeu-se que a tecnologia dos softwares é uma prática comum aos alunos, pois os recursos disponíveis na tela e os ícones são usuais para eles; apenas situações pontuais e de elaboração de fórmula tiveram relevância e dúvidas. 
Devido ao caráter de novidade, a utilização do software Calc para o ensino de Juros Simples e Compostos nos surpreendeu com relação ao grau de aprovação considerado pelos alunos, pois chamou a atenção o fato de os alunos não mencionarem dificuldades no trato e manuseio com 0 ambiente operacional do software, provavelmente por serem ícones de trabalho comuns a outros softwares e demonstrando, portanto, o quanto os alunos estão envolvidos com as tecnologias digitais.

A relação com a Mídia eletrônica é prazerosa - ninguém obriga que ela ocorra; é uma relação feita através da sedução, da emoção, da exploração sensorial, da narrativa - [...]. Mesmo durante o período escolar, a mídia mostra o mundo de outra forma - mais fácil, agradável, compacta, sem precisar fazer esforço [...] (MORAN; MASSETO; BEHRENS, 2001, p. 33)

Portanto, a planilha eletrônica oferece mais do que recursos importantes do ponto de vista pedagógico. 0 ensino de Juros Simples e Compostos por meio da metodologia Mídias Tecnológicas pode oferecer, portanto, a oportunidade de compreender a situação e, consequentemente, 0 conteúdo.

Conforme citado anteriormente, Teixeira (2015, p. 58) discorre que um dos motivos para "[...] utilizar as Planilhas Eletrônicas para 0 ensino de Matemática não é apenas o cálculo rápido e preciso, mas a redução do tempo gasto com cálculos repetitivos e já conhecidos".

Em consonância à afirmação, correlacionamos o fato de os alunos se preocuparem em entender a proposta de ensino e não apenas ficar fazendo "continhas", sem entender o contexto da operação matemática que envolve 0 cálculo.

Extrair dos recursos digitais o auxílio para o ensino de conteúdos requer planejamento. Portanto, a metodologia de ensino utilizada se revela um fator contribuinte de muita relevância no processo de aprendizagem. Evidencia-se, portanto, que a articulação adequada do recurso tecnológico como mediador no processo ensino da Matemática Financeira, Juros Simples e Compostos, tende a colaborar e contribuir com a aprendizagem efetiva dos conteúdos.

\section{CONSIDERAÇÕES FINAIS}

Retomando 0 objetivo geral deste trabalho em investigar a viabilidade de ensino de Juros Simples e Composto por meio da utilização do software Calc e da Sequência Didática elaborada como uma forma de articulação do ensino de conteúdos por meio das Mídias Tecnológicas, os resultados perpassam a ideia de uma simples metodologia de ensino, mas uma inovação para o ensino como algo que desconfigura uma prática tradicional de dar aulas, revelando o quanto as tecnologias digitais podem ser agregadas a esse processo, de modo a contribuir com o ensino e aprendizagem de conteúdos.

A metodologia de ensino revelou que os alunos podem construir conceitos e crescer em conhecimentos. Espera-se que o reflexo do que se aprende na escola, de algum modo tenha efeitos positivos na vida do aluno, com desdobramentos que busquem melhorar sua qualidade de vida e a escola é um dos meios pelo qual o aluno tem acesso a esse conhecimento útil para vivência fora da escola.

A educação e seus procedimentos de ensino não estão inertes ao processo de desenvolvimento tecnológico digital, fundamental para o desenvolvimento intelectual do aluno em uma escola. As práticas de ensino por meio das tecnologias digitais são formas motivadoras de aprendizagem aos alunos na busca de fazê-los compreender , entender o quanto os conteúdos, como os da Matemática Financeira, são úteis para eles e as planilhas eletrônicas de cálculo, no caso o software Calc, os 
permitem construir conhecimento e considerarem que tecnologias podem ser exploradas muito além da superficialidade quando integradas à aprendizagem dos conteúdos.

Em suma, os resultados da pesquisa revelam uma análise favorável do trabalho desenvolvido, aferindo que 0 uso das Planilhas Eletrônicas é adequado ao ensino da Matemática Financeira no que se refere aos conteúdos de Juros Simples e Compostos e para a construção autônoma e progressiva do conhecimento por parte dos alunos, os quais se mostraram agentes ativos do processo.

Isso posto, considera-se satisfatória e viável a utilização dos aportes empregados em todo o desenvolvimento da pesquisa, dando margem a intenções de futuros trabalhos para continuar a aprofundar conhecimentos sobre a utilização das tecnologias digitais dos softwares para 0 ensino de conteúdos matemáticos, sendo esses recursos tecnológicos digitais não substitutos do raciocínio pertinente a cada etapa escolar, mas elementos facilitadores e potencializadores da aprendizagem $\mathrm{e}$ formação das pessoas.

\section{REFERÊNCIAS}

BRASIL. Ministério da Educação. Secretaria de Educação Básica: Parâmetros Curriculares Nacionais de Matemática. Brasilia -DF. 2006. Disponível em: https://bit.ly/38pkVq6. Acesso em 10 de jun. 2016.

BRASIL. Ministério da Educação. Secretaria de Educação Básica: Base Nacional Comum Curricular. Brasília - DF. 2018. Disponível em: https://bit.ly/3kZttJz. Acesso em 30 de jan. 2021.

BORBA, Marcelo de Carvalho; PENTEADO, Miriam Godoy. Informática e Educação Matemática. 5. ed. Belo Horizonte: Autêntica. 2016.

BORBA, Marcelo de Carvalho; SILVA, Ricardo Scucuglia R.; GADANIDIS. Fases das tecnologias digitais em Educação Matemática. 2.ed. Belo Horizonte: Autêntica. 2018.

COELHO NETO, João; ALTOÉ, Anair. Construcionismo e a formação de professores: um estudo com alunos do curso de pedagogia da UENP CP. In: X CONGRESSO NACIONAL DE EDUCAÇÃO - EDUCERE, 2011, Curitiba. Anais..., Curitiba, 2011, p. 2316.

DIAS, Fabricio Ferreira. 0 uso da Planilha Eletrônica Calc no Ensino de Matemática no primeiro ano do Ensino Médio. 2013. Dissertação (Mestrado Profissional em Matemática) - Universidade Federal de Viçosa.

GENEROSO, Ana Amélia; COELHO NETO, João; REINEHR, Sheila; MALUCELLI, Andrea. Abordagem Qualitativa do uso das TDIC na Educação Básica. In: II Congresso Brasileiro de Informática na Educação. XIX Workshop de Informática na Escola, 2013, Unicamp. Anais..., Campinas, 2013, p. 230-233.

KENSKI, Vani Moreira. Educação e Tecnologias: 0 novo ritmo da Informação. 5. ed. Campinas: Papirus, 2015.

MARCHI, Vinicius Machacheski. Atividades Investigativas no Ensino da Matemática Financeira: as estratégias empregadas com uso de Planilhas Eletrônicas. 2014. Dissertação (Mestrado Profissional em Matemática) - Universidade Estadual de São Paulo.

MORAES, Roque; GALIAZZI, Maria do Carmo. Análise Textual Discursiva. 2. ed. Ijuí; Unijuí, 2014. 
MORAN, José Manuel; MASETTO, Marcos T.; BEHRENS, Marilda Aparecida. Novas Tecnologias e mediação pedagógica. 21 ed. São Paulo: Papirus, 2001.

PARANÁ, Secretaria de Estado da Educação. Diretrizes Curriculares de Matemática para a Educação Básica. Curitiba: SEED, 2008. Disponível em: http://www.seed.pr.gov.br/portals/portal/semana/t_matematica.pdf. Acesso em 8 de set. de 2016.

REIS, Simone Regina. Atividades Investigativas no Ensino da Matemática Financeira: as estratégias empregadas com uso de Planilhas Eletrônicas. 2013. Dissertação (Mestrado Profissional em Matemática) - Universidade Federal de Santa Maria.

TEIXEIRA, Enilton de Abreu; Uso da Planilha Eletrônica Excel como ferramenta didática para 0 ensino da Matemática Financeira no ensino médio. 2015. Dissertação (Mestrado profissional em Ensino) - Universidade Federal do Tocantins.

VALENTE, José Armando. 0 Computador na Sociedade do Conhecimento. 6. ed. Campinas, SP. NIED, 1999.

ZABALA, Antoni. A Prática Educativa: como ensinar. 2. ed. Porto Alegre: Ed. Artmed, 2010.

RECEBIDO EM: 26 dez. 2020

CONCLUÍDO EM: 06 fev. 2021 
